\title{
MUCOSECTOMY IN COMPLICATED APPENDICITIS
}

\author{
Fahad Ali Khan, Syeda Rifaat Qamar Naqvi*, Ayesha Khan*, Babar Sultan**, Anam Haider***, Rehana Khadim***, Palwasha Khan****, \\ Zaheer Ud Din Qureshi** \\ Pakistan Institute of Medical Sciences, Islamabad Paksitan, *Combined Military Hospital/National University of Medical Sciences (NUMS) Rawalpindi Pakistan, \\ ${ }^{* *}$ Ayub Medical Complex Abbottabad Pakistan, ${ }^{* * *}$ Army Medical College/National University of Medical Sciences (NUMS) Rawalpindi Pakistan, ****Abu Usman \\ Hospital Peshawar Pakistan
}

\begin{abstract}
Objective: To describe the technique and results of mucosectomy; A surgical technique that is easy to perform, and has a lower morbidity and complication rate as compared to standard appendectomy in cases of complicated appendicitis.

Study Design: Quasi-experimental study.

Place and Duration of Study: Surgical - A Unit, Ayub Teaching Hospital, in Abbottabad, from Mar 2017 to Mar 2019.

Methodology: Patients included were those who presented with appendicular mass, phlegmon, recurrent appendicitis, appendicitis in uncommon locations, presence of adhesions, those cases of appendicular mass and phlegmon which was either not responding to medical treatment, or diagnosed per operatively being clinically not palpable or not seen on ultrasound. Per operative and post-operative variables were documented and analyzed. In mucosectomy, thesubserosal portion of the appendix i-emuscularis and mucosa of the appendix was dissected out from the serosa after ligation of the appendicular base, or ligation done after delivering the appendix out of the serosa. The serosa that was adherent to the surrounding gut, omentum or other viscera was left intact.

Results: A total of 192 patients were included in this study, half of which underwent standard appendectomy and a mucosectomy was performed on the rest. The mean time of surgery was $30 \pm 1.2 \mathrm{~min}$ as compared to the standard appendectomy group (55min \pm 3.6 ). More than half of the patients undergoing standard appendectomy required extension of the incision $(56.2 \%)$, and only $8 \%$ required so from those on whom mucosectomy was performed. Per operative hemorrhage was seen in $32.2 \%$, however inmucosectomy group only $1 \%$.

Conclusion: Mucosectomy is a safer modification of standard appendicectomy in patients with appendicular mass, early mass formation, phlegmon, recurrent appendicitis and where the appendix is in an uncommon site, inflamed and adherent.
\end{abstract}

Keywords: Appendicular mass, Appendectomy, Mucosectomy, Phlegmon.

This is an Open Access article distributed under the terms of the Creative Commons Attribution License (http://creativecommons.org/licenses/by/4.0), which permits unrestricted use, distribution, and reproduction in any medium, provided the original work is properly cited.

\section{INTRODUCTION}

Appendectomy has been the standard treatment for acute appendicitis for over a century. More than 300,000 appendectomies are performed annually in the United States ${ }^{1}$. Although appendectomy is generally well tolerated, it is a major surgical intervention and can be associated with postoperative morbidity 2,3 .

Appendicitis is inflammation of the appendix, and it is the most common abdominal surgical emergency, with a lifetime risk of $8.6 \%$ in male and $6.9 \%$ in females. Gold Standard management is primarily surgical ${ }^{3,4}$, although some centers advocate conservative medical therapy ${ }^{5,6}$.

Operation in cases of appendicular masses is harder to perform. The adhesions seen in such cases require extension of the incision, difficult serosal dissection, and mobilization of the caecum which leads to delayed discharge, higher morbidity, pain, and ileus ${ }^{7,8}$. Removal of the appendix using the 'mucosectomy'

Correspondence: Dr Syeda Rifaat Qamar Naqvi, Surgery Department, Combined Military Hospital Rawalpindi Pakistan

Received: 23 Apr 2021; revised received: 25 Apr 2021; accepted: 26 Apr 2021 technique developed in our Surgical unit that is carried out by avulsion and removal of the appendix out of its serosa leaving it behind decreases gut handling, chances of gut injury and lesser bleeding.

This study was performed to find a better way of dealing with complicated appendicitis cases, in which standard appendectomy is sometimes very difficult and associated with a high rate of complications. $\mathrm{Mu}-$ cosectomy in such cases may prove a safer and easier approach.

\section{METHODOLOGY}

This quasi-experimental study was performed at Surgical - A Unit, Ayub Teaching Hospital, in Abbottabad from March 2017 to March 2019. One Hundred Ninty Two patients; 96 patients underwent standard open appendectomy and mucosectomy was performed on the rest of the cases. The sample size was calculated using WHO sample size calculator. Patients were recruited through consecutive sampling. Institutional Ethics Review Board permission was taken from the Ayub Teaching Hospital, Abbottabad. Inclusion criteria were; cases with matted appendix, adhesions such 
as recurrent appendicitis, appendicular mass, phlegmon, and adherent appendix in unusual positions such as subhepatic appendix. Exclusion criteria were uncomplicated appendicitis, cases with frozen pelvis.

Per operative and postoperative variables were documented and analyzed at the completion of the study. Informed consent was taken from all the patients.

Standard Surgical management was taken to be prograde appendectomy. Prograde appendectomy remains the surgical choice for inflamed appendix when the tip is easily identified and mobilized. Retrograde appendicectomy is chosen when the tip is inaccessible.

Prograde mucosectomyis the procedure we advocatein this study, in cases where the appendix was matted and adherent such as recurrent appendicitis, appendicular mass, phlegmon or adherent appendix in unusual positions such as subhepatic appendix. When the serosa of the appendix is adherent, but the tip is accessible, we identified the tip and made an incision into the serosa. Then we delivered the subserosal portion of the appendix out of the serosa and followed it backwards towards the base. This was then ligated, cut at the base and subsequently removed while leaving the serosa behind.

In similar cases where the tip was matted and inaccessible, retrograde mucosectomy is easier to
Data was entered in SPSS-21. Quantitative variables were summarized as mean $\pm \mathrm{SD}$. Qualitative variables were summarized as number and percentage. Independent sample t-test was applied for quantitative variables while chi-square test was applied for qualitative variables.

\section{RESULTS}

A total of 192 patients were included, half of which underwent standard appendicectomy and mucosectomy was performed on the rest. Average age of the patients was $27 \pm 3.5$ years that included 108 $(56.2 \%)$ males and $84(43.8 \%)$ females. The mean time of surgery was statistically significantly lesser in the mucosectomy group (30 $\mathrm{min} \pm 1.2$ ) as compared to the standard appendectomy group $(55 \mathrm{~min} \pm 3.6) p<0.01$ shown in table-I. Chances of per operative hemorrhage were higher in the standard appendectomy group 9 $(9.3 \%)$ than the mucosectomy group only $1(1 \%)$ $p=0.009$. Gut injury was seen in $11(11.4 \%)$ in standard appendectomy group and none in mucosectomy group $p=0.002$. More than half of the patients undergoing standard appendectomy required extension of the incision $54(56.2 \%) p<0.01$, and only $15(8 \%)$ required so from those on whom mucosectomy were performed, Wound infection rates were almost the same, but chronic abdominal pain was seen more often in the standard appendectomy group shown in table-II.

Table-I: Comparison time of surgery between mucosectomy and standard appendectomy.

\begin{tabular}{|c|c|c|c|c|c|}
\hline & \multicolumn{2}{|c|}{$\begin{array}{c}\text { Mucosectomy n }(\%) \\
n=96\end{array}$} & \multicolumn{2}{|c|}{$\begin{array}{l}\text { Standard Appendectomy n }(\%) \\
n=96\end{array}$} & $p$-value \\
\hline Time of Surgery & \multicolumn{2}{|c|}{ 15-45min (mean $30 \mathrm{~min} \pm 1.2)$} & \multicolumn{2}{|c|}{$25-85 \min (\operatorname{mean} 55 \mathrm{~min} \pm 3.6)$} & $<0.01$ \\
\hline \multicolumn{6}{|c|}{ Table-II: Comparison of complication between mucosectomy and standard appendectomy. } \\
\hline & & \multicolumn{2}{|c|}{$\begin{array}{l}\text { Mucosectomy } \\
\text { n (\%), n=96 }\end{array}$} & $\begin{array}{c}\text { Standard Appendectomy } \\
\text { n (\%), n=96 }\end{array}$ & $p$-value \\
\hline \multicolumn{2}{|c|}{ Significant per operative hemorrhage } & \multicolumn{2}{|c|}{$1(1 \%)$} & $9(9.3 \%)$ & 0.009 \\
\hline \multicolumn{2}{|l|}{ Gut injury } & \multicolumn{2}{|c|}{-} & $11(11.4 \%)$ & 0.002 \\
\hline \multicolumn{2}{|l|}{ Enteric Fistula } & \multicolumn{2}{|c|}{-} & $1(1 \%)$ & 0.47 \\
\hline \multicolumn{2}{|l|}{ Wound infection } & \multicolumn{2}{|c|}{$6(6.2 \%)$} & $7(7.2 \%)$ & 0.77 \\
\hline \multicolumn{2}{|c|}{ Need for extending the incision } & \multicolumn{2}{|c|}{$8(8.3 \%)$} & $54(56.2 \%)$ & $<0.01$ \\
\hline \multicolumn{2}{|c|}{ Chronic abdominal pain suggesting adhesions } & \multicolumn{2}{|c|}{$4(4 \%)$} & $8(8.3 \%)$ & 0.23 \\
\hline
\end{tabular}

perform. We identified, ligated and cut the base. Then wedissected and removed the subserosal portion of the appendix leaving the serosa behind.

Using this technique there is minimal handling of the gut since dissection inside the serosa does not require delivering the ileum, cecum orileocecal junction out of the abdomen. In addition, since the structures outside the serosa are not tampered with, there is no manipulation of the mesoappendix which means there is lesser bleeding.

\section{DISCUSSION}

This is a novel study and very scarce literature is available on alternative techniques to a standard appendectomy in appendicular masses. We performed this study to describe the technique and results of mucosectomy; which is easier to perform, has a lower morbidity and complication rate. From this study, we have found that mucosectomy is a safer alternative to standard appendectomy in cases complicated by matting of appendix and cases with adhesions such as recur- 
rent appendicitis, appendicular mass, phlegmon, and adherent appendix in unusual positions such as sub hepatic appendix.

Appendectomy is the standard surgical management of appendicular pathology ${ }^{3}$. Most centers advocate emergency appendicectomy in all cases of appendicitis $^{3,4}$, while others opt for a conservative approach initially ${ }^{5}$. Patients presenting with appendicular mass, phlegmon or adherent appendix undergoing emergency surgery have a prolonged stay and increased morbidity and a higher rate of complications as compared to routine appendicectomy on uncomplicated acute appendicitis 6 . Emergency surgery has a certain place in the treatment of appendiceal mass and abscess. High frequency of postoperative complications is the negative side of this method. These complications are caused by edema and the vulnerability of the adjacent small and large intestine, and difficult approach to the appendix due to deformation of anatomic structures and location. Conducting colonic resections (iliocecectomy, right hemicolectomy) is sometimes necessary instead of appendectomy due to the acute inflammation and adhesion. The proponents of surgical intervention compared to conservative treatment argue that there is no need of longitudinal follow-up and repeated hospitalizations. Surgery in such cases also avoids misdiagnosed cases and promptly deals with any unexpected ileocecal pathology that masquerades as an appendiceal mass. A more extensive incision, immaculate serosal dissection, bleeding and inadvertent gut injury are faced in these cases that lead to higher morbidity with a greater chance of paralytic ileus-10.

Surgery in masses is still controversial, with many surgeons advocating a conservative approach ${ }^{8,9}$, leading to an interval appendicectomy ${ }^{11}$ and others in favor of surgery to prevent recurrence of symptoms, complications, or the need for return for interval appendicectomy for which most cases are lost to follow up ${ }^{12-15}$.

Surgery on complicated appendicitis is difficult technically and has a higher complication rate and morbidity ${ }^{6}$. Between the two approaches, ante grade appendicectomy remains the standard technique for adherent and inflamed appendices where the tip is easy to access. The retrograde approach is used alternately in those cases where the tip is inaccessible ${ }^{16}$. In patients with serosaladhesions and masses, mucosectomy is a superior technique. The technique is easy, quick to perform, and safe without needing an extension of the incision in most cases. The caecum is not mobilized and dissection is not needed to break adhesions between serosa and surrounding gut, so there is minimal visceral handling with very little chance of gut injury. Haemostasis is also easy, as mesoappendix is not tampered with when the serosa is not removed ${ }^{17,18}$.

This study, thus, proves that in appendicitis cases complicated by appendicular mass, phlegmon, recurrent appendicitis, and in cases of appendicitis in uncommon locations and presence of adhesions, mucosectomy is a much safer alternative, and a procedure that is easy to perform and with an easy learning curve according to our experience. Several complications can be avoided including certain serious conditions such as gut injuries and enteric fistulas that lead to prolonged morbidity.

\section{CONCLUSION}

Appendicectomy in patients with appendicular mass, phlegmon, recurrent appendicitis, and in cases of appendicitis in uncommon locations and presence of adhesions is difficult with extensive serosal adhesions that requires a bigger incision, delivering the gut out of the abdomen and dissection into the adhesions that leads to ileus, visceral damage, bleeding and increased morbidity. Mucosectomy of the appendix, either retrograde or prograde, avoids extensive dissection leading to lesser morbidity and no chances or visceral injury or any other complication. We recommend mucosectomy, either prograde or retrograde depending on the pathological anatomy, as a safer modification of routine appendicectomy in such patients.

\section{CONFLICT OF INTEREST}

This study has no conflict of interest to be declared by any author.

\section{REFERENCES}

1. Pitts SR, Niska RW, Xu J, Burt CW. National hospital ambulatory medical care survey: 2006 emergency department summary. Natl Health Stat Report 2008; 7: 1-38.

2. Murao Y, Ueda S, Miyamoto S. Preoperative administration of antibiotics in patients with suspected acute appendicitis. Surg Today 1996; 26(5): 314-22.

3. Matthew Fields J, Davis J, Alsup C. Accuracy of point-of-care ultrasonography for diagnosing acute appendicitis: a systematic review and meta-analysis. Acad Emerg Med 2017; 24(9): 1124-36.

4. Fitzmaurice GJ, Hurreiz BMH, Epanomeritakis E. Antibiotics versus appendectomy in the management of acute appendicitis: a review of the current evidence. Can J Surg 2011; 54(5): 307-14.

5. Salminen P, Paajanen H, Rautio T. Antibiotic therapy vs appendectomy for treatment of uncomplicated acute appendicitis; The APPAC randomized clinical Trial. J Am Med Assoc 2015; 313(23): 2340-48.

6. Tannoury J, Abboud B Treatment options of inflammatory appendiceal masses in adults. World J Gastroenterol 2013; 19(25): 3942-50. 
7. Ellis BW, Acute Appendicitis. In Hamilton Bailey's Emergency Surgery $12^{\text {th }}$ ed. Oxford: Butterworth-Heinemann. 1995; 411-23.

8. Fihri MJF, Elguazzar A, Ramraoui ME, Mejdane A, Barni RE, Khader AE. Management of inflammatory appendiceal mass: a retrospective study. Int J Med Sci Clin Inv 2017; 4(5): 2949-52.

9. Gorter RR, Eker HH, Gorter-Stam MA, Abis GS, Acharya A, Ankersmit M, et al. Diagnosis and management of acute appendicitis. EAES consensus development conference 2015. Surg Endosc 2016; 30(11): 4668-90.

10. Andersson RE, Petzold MG. Nonsurgical treatment of appendiceal abscess or phlegmon: a systematic review and meta-analysis. Ann Surg 2007; 246(5): 741-48.

11. Vargas HI, Averbook A, Stamos MJ. Appendiceal mass: conservative therapy followed by interval laparoscopic appendectomy. Am Surg 1994; 60(10): 753-58.

12. Samuel M, Hosie G, Holmes K. Prospective evaluation of nonsurgical versus surgical management of appendiceal mass. J Pediatr Surg 2002; 37(6): 882-86.
13. Sallinen V, Akl EA, You JJ, Agarwal A, Shoucair S, Vandvik PO, et al. Meta-analysis of antibiotics versus appendicectomy for non-perforated acute appendicitis. Br J Surg 2016; 103(6): 656-67.

14. El Hentour K, Millet I, Pages-Bouic E, Curros-Doyon F, Molinari $\mathrm{N}$. How to differentiate acute pelvic inflammatory disease from acute appendicitis ? A decision tree based on CT findings. Eur Radiol 2018; 28(2): 673-82.

15. Bailey and Love's Short Practice of Surgery. CRC Press. 2012. p. 1209.

16. Harnoss JC, Zelienka I, Probst P, Grummich K, Müller-Lantzsch C, Harnoss JM, et al. Antibiotics versus surgical therapy for uncomplicated appendicitis. Ann Surg 2017; 265(5): 889-900.

17. Teixeira FJR, Couto SD. Acute appendicitis, inflammatory appendiceal mass and the risk of a hidden malignant tumor: a systematic review of the literature. World J Emerg Surg 2017; 12: 12.

18. Depinet H, Copeland K, Gogain J. Addition of a biomarker panel to a clinical score to identify patients at low risk for appendicitis. Am J Emerg Med 2016; 34(12): 2266-71. 